International Journal of Critical Indigenous Studies

Volume 9, Number 2, 2016

\title{
National Indigenous Research Knowledges Network (NIRAKN)-Some Reflections and Learnings
}

Author

Aileen Moreton-Robinson

Queensland University of Technology, Indigenous Research and Engagement Unit

\section{Autobiographical note}

\section{Distinguished Professor Aileen Moreton-Robinson, Queensland University of Technology, Australia}

Professor Aileen Moreton-Robinson is a Goenpul woman from Minjerribah (Stradbroke Island), Quandamooka First Nation (Moreton Bay) in Queensland, Australia. She is presently the Dean of Indigenous Research and Engagement at the Queensland University of Technology (QUT) and was the first Australian Indigenous scholar to be awarded the title 'Distinguished Professor' in 2016 in recognition of her international standing in Indigenous studies and research, and for advancing opportunities for Indigenous students to undertake postgraduate studies.

Moreton-Robinson's work is multidisciplinary and covers areas including law, sociology, feminism, Indigenous studies, Australian studies and history. She has been instrumental in critical whiteness studies in Australia and, under her leadership, the Australian Critical Race and Whiteness Studies Association was founded; she is the current ACRAWSA President. Her 1999 book, Talkin' Up to the White Woman, was shortlisted for the New South Wales Premier Literary Awards and the W.E.H. Stanner Award; it is a seminal text in the area. MoretonRobinson's most recent book, The White Possessive: Property, Power and Indigenous Sovereignty was awarded the '2015 Best Subsequent Book in Native American and Indigenous Studies Prize' at the annual Native American and Indigenous Studies Association (NAISA) conference 2016. She is a former member of Native American and Indigenous Studies Association Council and executive member of the National Aboriginal and Torres Strait Islander Higher Education Consortium. Moreton-Robinson is the founder and co-editor, with Dr Mark McMillan, of the International eJournal of Critical Indigenous Studies and is the Director of the Australian Research Council funded National Indigenous Research and Knowledges Network (NIRAKN) at QUT.

\section{Abstract}

This paper outlines the historical and policy context of the Australian Research Council funded National Indigenous Research and Knowledges Network (NIRAKN). Key learnings from four years of NIRAKN's existence are set out, followed by a review of the higher education sector's Indigenous research capacity building initiatives more generally.

Except where otherwise noted, content in this journal is licensed under Creative Commons Attribution 4.0 International Licence. As an open access journal, articles are free to use with proper attribution.

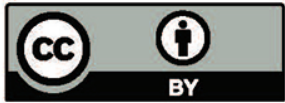

(c) The Author(s) 2016 https://doi.org/10.5204/ijcis.v9i2.135 


\section{Keywords}

Indigenous, Aboriginal, research capacity, research.

\section{Background}

In 2003, the Australian Research Council (ARC), under its network funding scheme, called for applications to research networks from the higher education sector. A small number of applications were made by Indigenous researchers, many of whom were members of the then National Indigenous Higher Education Network (NIHEN), now formally incorporated as the National Aboriginal and Torres Strait Islander Higher Education Consortium (NATSIHEC). Applications were submitted in March 2004, but were not successful. In 2004 and 2005 the current Director of NIRAKN, Distinguished Professor MoretonRobinson, had a discussion about the need for an Indigenous research network with the then Chair of the ARC, Professor Graeme Turner, and the then Chief Executive Officer, Professor Mandy Thomas. As an outcome of these discussions and upon her appointment to Professor of Indigenous Studies at QUT in 2006, Moreton-Robinson began building an online Indigenous Studies Research Network (ISRN) consisting of international and national Indigenous scholars, while delivering a postgraduate research capacity building program. The ISRN website went live in 2009.

The prospect of a national Indigenous researchers' network had been the subject of discussion since the late 1970s and it continued to gather momentum. The second council of the Indigenous Higher Education Advisory Council (IHEAC) instigated a scoping study in 2008. Two members of the council had participated in the ISRN's capacity building program in 2007: Professor John Maynard and Professor Maggie Walter. The ISRN research capacity building program and the Melbourne University's Indigenous research summer school were the only two programs in the sector at the time. The need for improving Indigenous research outcomes was firmly placed on IHEAC's agenda in 2008 and a scoping study was commissioned and led by the Council's members, Professor Maggie Walter and Professor Bonnie Robertson (IHEAC 2008). The scoping study's final report was released in 2009; it highlighted and outlined the research capacity building program of the ISRN stating that:

The Indigenous Studies Research Network is the Australian Indigenous research entity most closely aligned with the vision for an ICRD [Indigenous Center for Research \& Development]. Collaboration rather than competition is the key here. The national focus, sector profile and links of the ICRD would enable existing strengths of the ISRN to be developed and broadened in their impact and coverage. A consultative site visit to the ISRN Director in October 2008 suggested that there would be strong synergies and that a collaborative arrangement would be possible and welcomed (Walter \& Robinson 2009, 25).

Unfortunately, the scoping study's recommendation to establish a centre for research and development was rejected by the ARC. However, the third Indigenous Advisory Council remained committed to the concept of an Indigenous research network. The Chair of IHEAC, Professor Steve Larkin, met several times with the then ARC Chief Executive Officer, Professor Margaret Shields, who finally agreed to explore the idea of a network. Professor Moreton-Robinson (as Deputy Chair of the Council) chaired a meeting with ARC representatives and a small number of Indigenous scholars in Canberra. The aim of the meeting was to discuss the concept and need for an Indigenous researchers' network. As a result of this meeting, and efforts by the third IHEAC members, the ARC called for 
expressions of interest (EOI) for a special research initiative for an Aboriginal and Torres Strait Islanders research network on 29 December, 2012.

Professor Moreton-Robinson drafted and finalised the Queensland University of Technology (QUT) led EOI, naming the network the National Indigenous Research and Knowledges Network (NIRAKN). The EOI was successful. The ARC requested the development of a full application and finally awarded the grant to NIRAKN. NIRAKN was launched by the Chief Executive Officer of the ARC at the Australian Institute of Aboriginal and Torres Strait Islander Studies in July 2013. The aims of NIRAKN are:

1. Establish a coterie of skilled, qualified Indigenous researchers creating pathways from undergraduate to postgraduate studies to establish a regenerative pipeline of new researchers, across institutions, the nation and fields of critical research importance.

2. Deliver a program of research capacity building in order to develop a critical mass of multidisciplinary, qualified Indigenous researchers to meet the compelling research needs of our communities.

3. Connect Indigenous researchers nationally and internationally to develop culturally supportive, inclusive research environments, which enable cross fertilisation of ideas and provide platforms for new Indigenous multidisciplinary research.

4. Begin setting the Indigenous research agenda by applying Indigenous knowledges and expertise to multidisciplinary, collaborative projects directed at compelling the research needed to inform community and government policy and program delivery.

5. Develop an ongoing, integrated research program of collaborations with partner organisations through the ARC, NHMRC, government, industry, community and philanthropic grant funding.

6. Achieve national and international recognition as the centre of Australian Indigenous research expertise, knowledge and innovation.

\section{Learnings from NIRAKN: Increasing the Indigenous research workforce}

Over the past four years during which NIRAKN has operated, it is apparent that the Indigenous research workforce is in its infancy. The review of higher education access and outcomes for Aboriginal and Torres Strait Islander people (Behrendt et al. 2012, 9) reported that Indigenous people are underrepresented in higher degrees by research and there is an urgent need to raise the number of Indigenous people undertaking and completing post-graduate studies. NIRAKN has played its part in promoting and supporting the cohort of post-graduate students that were enrolled in a PhD or Masters by Research in 2013 and subsequent enrolments in the following years. In 2013 the commencement rate for PhDs was 54 with a total of 321 continuing and for Masters by Research commencing students were 28 in number and 115 in total. The completion rate for 2013 PhDs was 29 and for Masters by Research, 6. In 2014 the commencement rate for PhDs was 94 with a total of 365 students and for Masters by Research commencing students were 41 in number, with a total of 121. The completion rate for PhDs in 2014 was 27 and Masters by Research, 7. In 2015 the commencement rate for PhDs was 75 with a total enrolment of 389 and for Masters by Research commencing students were 35 in number and 111 in total. While the Indigenous PhD and Masters by Research commencement rates have improved at current rates of increase, the numbers of Indigenous researchers needed to reach critical mass are many generations away. The completion rate is 
improving over time, but the difference between commencement and completions indicate that there is a high rate of attrition.

The trend appears to be a widening gap between Indigenous PhD and Masters' enrolment and completions. However, there is a lack of information about what proportion of this gap is due to the growth in commencement rates and the lag of completions tailing commencements by a period of four or more years. Further, the data does not identify inactive research students-students who have enrolled, but are deferring studies. More research is needed to determine the rate of attrition, deferrals and inactive Indigenous students and to study the factors affecting withdrawal from studies and the length of time taken by Indigenous people to complete higher degrees by research. The median for full time non-Indigenous students to complete PhDs is five years. On current statistics the trend seems to point to Indigenous postgraduates completing within five to eight years full-time.

While the PhD journey for all students is a long, complex and arduous one with significant attrition, Indigenous PhD candidates face additional barriers to their non-Indigenous peers. The anecdotal evidence discerned through the NIRAKN Research Capacity Building Workshops strongly suggests that many Indigenous academics enrolled in PhDs often find it difficult to complete their studies given their diverse workload demands. These include demands common to all academics, such as the increasing pressure to publish, obtain research grants and have higher degree qualifications-as well as those specific to the Indigenous community, such as other student support, mentoring, governance and community engagement roles. Universities do not often recognise nor factor into workload allocation metrics the added demands on Indigenous staff. In addition, as most of the Indigenous academic staff who have PhDs are early career researchers, there are only a small numbers of Indigenous academics who are willing to supervise Indigenous postgraduates as principal supervisors and act as role models. Approximately 350 Indigenous scholars hold PhDs, but the vast majority are early to mid-career researchers. As the last Aboriginal and Torres Strait Islander Advisory Committee to the Minister for Education noted in their submission on growing the Indigenous academic workforce:

The increase of workloads and higher demand for academic staff to do multiple research projects and teach in classes could reduce the capacity for new research on Indigenous issues. This could lead to situations where Indigenous academics who are seeking to engage in new research projects may receive less support by universities and other players in academe. Already stretched senior Indigenous academics may find it difficult to make time to mentor and advise new Indigenous academics on research methods, grant application, funding and publication matters resulting in higher rates of attrition among new Indigenous researchers. (ATSIHEAC 2015, 9)

Discussions with Indigenous postgraduate students who attended the workshops (who totalled 93) identified a number of inhibiting factors that can be said to contribute to the high attrition rate. Most Indigenous postgraduate students have principal supervisors who are non-Indigenous and, as subsequent research has found, these usually have an unacceptably low level of cultural competence. This is compounded by a lack of peer support networks for emerging Indigenous researchers and postgraduates, and instances of institutional racism within the university that marginalises or excludes Indigenous knowledge and creates a burden of stress on Indigenous researchers. The Indigenous postgraduate network established through NIRAKN has enabled peer support and fostered an exchange of ideas. 
One of NIRAKN's aims was to build a pipeline transitioning postgraduate students to become academic researchers, but capacity to fulfil this aim was circumscribed by institutional impediments:

1. Universities are not actively welcoming and supportive of Indigenous postgraduate students and, as a result, students experience a lack of confidence, cultural isolation and alienation.

2. Most of the research supervision is provided by non-Indigenous supervisors who may not understand the type or foundation of the research Indigenous people wish to undertake.

3. Assessors and supervisors lack an understanding of, or refuse to consider, the intellectual merits of Indigenous research methodologies and Indigenous knowledges and protocols.

4. Universities do not have a sufficient number of Indigenous role models within academe and do not include Indigenous research as part of research core business.

5. Universities do not provide opportunities for regular contact with other Indigenous postgraduates.

6. The university environment is often a difficult and complex space for Indigenous people, as the dominant knowledge system has its roots in Western theories and epistemologies.

7. Indigenous postgraduate students often carry heavy workloads; such duties relate to committee membership and additional responsibilities to their communities.

8. Indigenous postgraduate students are often their families' main financial supporter throughout their studies and usually experience financial stress to spatial relocation.

To this end, NIRAKN worked with NATSIHEC to develop strategies that could give effect to structural changes within the sector. As Director of NIRAKN and executive member of NATSIHEC with the research portfolio, I have undertaken an increasingly important advocacy role in the tertiary sector. NIRAKN has sought to raise the profile of Indigenous research and provide advice to the government and others regarding the research environment and academic terrain facing Indigenous scholars. The network is actively engaged in bringing about change in the culture of the Australian higher education sector and it is with this advocacy role in mind that NIRAKN and NATSIHEC made submissions to the Review of Australia's Research Training System (McGagh et al. 2016) conducted by the Australian Council of Learned Academies. NIRAKN had noted the concerns of the Research Training System and responded by instituting a national research capacity building program and undertaking research through a small grants scheme. The program continues to involve introductory level research skills workshops delivered to Indigenous postgraduates nationally by the NIRAKN hub; a series of advanced research workshops; Indigenous research methodologies, masterclasses, critical reading groups and research residencies; as well as access to networking, mentoring and the provision of other professional resources. The success of the program has gone some way to alleviating the sense of isolation felt by many of the participants, as well as enhancing their research skills and strengthening their sense of belonging in the academy.

NIRAKN cannot hope to compensate for the shortcomings in the long term, so recommends dedicated provision within the Research Training Scheme for Indigenous research capacity building. Ring-fenced funding would oblige universities to set up programs that would also draw on mainstream funds, rather than the present situation 
where there is an almost exclusive reliance on supplementary funding to provide for Indigenous higher education. In tandem, institutions should seek to introduce cultural competency training for non-Indigenous supervisors who continue to preponderate in the supervision of Indigenous students. Sectoral readiness for such training was noted by QUT when it recently submitted an Office for Learning and Teaching (OLT) Seed Grant Proposal to build non-Indigenous supervisory capacity. The Research Training System should make provision for the development of an Indigenous supervisory skills framework at every university. As financial stress remains an impediment to participation, NIRAKN recommends streamlining the number of Indigenous Commonwealth scholarships, so that the monetary value of those retained is increased. Additionally, ABSTUDY needs to be more flexible and the funding increased to include post-graduate students.

NIRAKN and NATSIHEC have continued this advocacy work with Universities Australia (UA) and advised UA that what the sector required was a coherent Indigenous strategy. Several meetings took place between UA staff and NATISHEC and, in March 2017, UA launched its sector-wide Indigenous Strategy 2017-2020 (Universities Australia 2017). The strategy contains a number of initiatives that should enable Indigenous researchers and research to flourish. UA's member universities are committed to:

- maintain institutional growth rates for Aboriginal and Torres Strait Islander peoples' enrolment that are at least 50 per cent above the growth rate of non-Indigenous student enrolment, and ideally 100 per cent above;

- aim for retention and success rates for Aboriginal and Torres Strait Islander students equal to those of domestic non-Indigenous students in the same fields of study by 2025;

- aim to achieve equal completion rates by fields of study by 2028 ;

- include Indigenous higher education, research and employment as priority areas in core policy areas, including institutional strategic and business plans;

- have Indigenous Research Strategies in place 2018;

- ensure that implementation of these plans and policies is devolved through the university's faculties, schools and units;

- ensure that the workload expected of Aboriginal and Torres Strait staff is recognised in workload planning and in performance assessments and promotions processes;

- build robust, respectful and collaborative partnerships between themselves and the Aboriginal and Torres Strait Islander communities that they serve;

- take a community leadership role in promoting Indigenous higher education and building opportunities for wider community engagement in it;

- have current executive staff and all new senior staff complete cross-cultural training programs from 2018; and

- have processes that ensure all students will encounter and engage with Aboriginal and Torres Strait Islander cultural content as integral parts of their course of study, by 2020. (Universities Australia 2017:14)

\section{Indigenous studies research}

The cohort of Indigenous researchers is small, but growing, and our capacity to win nationally competitive grants is increasing. The Australian Research Council (ARC) received a total of 32 proposals for Discovery Indigenous in 2015, 26 in 2014 and 32 in 2013. The overall success rate of $31.3 \%$ represents a decrease from the success rate of 
$38.5 \%$ in the previous round due to a greater number of proposals being received in this round. Additionally, there was a decrease in the total value of funding for Discovery Indigenous 2015 of $\$ 4.39$ million compared with the previous round of $\$ 4.89$ million. Successful grants won under the Indigenous Discovery and Discovery schemes between 2013 and 2015 reveal that Indigenous research is predominantly in public health and health services, linguistics, historical studies, cultural studies, specialist studies in education, law and anthropology.

What is important to note is that the work undertaken by NIRAKN has seen some tangible outcomes: Indigenous research is beginning to flourish. Out of the 10 applications funded in the 2015 round of Discovery and Indigenous Discovery grants, 50\% of the successful Indigenous Discovery grants were secured by teams with at least one NIRAKN member. These grants received a total of $\$ 1,558,382$, representing $35.4 \%$ of the total funds awarded. NIRAKN members secured the largest grant for an Aboriginal and Torres Strait Islander topic under the Discovery scheme. This grant is $16.3 \%$ of the total funds directed to Indigenous research through this scheme. In 2016, three of the 11 projects funded were awarded to NIRAKN members, Dr Linda Ford, Dr Shino Konishi and Professor Kim Scott.

\section{The higher education research policy context in 2017}

In the joint Department of Industry and Department of Education policy paper entitled Boosting the Commercial Returns from Research (2014:3), it states that research produced within the education sector is "overall, ... highly productive, internationally connected, and recognized globally for high quality research". Our publicly funded research agencies, such as the CSIRO, are mission-directed and tend to have focus on generating commercial outcomes. Our universities serve the national interest in many ways, including by generating new ideas that have long-term implications and by producing focused research that, for example, contributes to better public health and wellbeing. Australia performs strongly in research excellence, but we perform poorly by international standards in translating publicly funded research into commercial outcomes. The policy paper argues that:

To improve the commercial outcomes from publicly funded research, the underlying incentives must shift. The settings that underpin incentives for research-industry collaboration, such as grant mechanisms, should be adjusted. We should also examine the regulatory setting that influence entrepreneurship. $(2014,21)$

There is also value in better articulating Australia's research priorities. We cannot research everything and should focus research in the national interest. The best minds from across research, industry and government should formulate a set of high level priorities and corresponding important research challenges for Australia. These challenges should be practical problems that capture our research and business communities. Long-term change will be best achieved by system-wide adjustment. Articulating priorities and adjusting system settings, such as grant funding formulae, should generate a lasting shift in research focus and collaboration, while maintaining and enhancing Australia's reputation for research excellence.

In its submission to the Senate Committee of Inquiry into Higher Education and Research Reform Amendment Bill 2014, UA argued "that stable and properly funded research programs are critical for achieving national economic, social and cultural success" $(2014,18)$. UA recommended to the Senate Committee that it should "oppose any further reduction in research funding including in providing offset savings for proposed cuts to 
higher education that do not proceed". These include the ARC and NHMRC nationally competitive grant schemes (UA 2014, 18).

It is clear from the UA policy statements that there is agreement within the higher education sector that high quality research is a driver of innovation. It is driven by and supports talented people. It generates international linkages. It yields more breakthroughs and provides new ideas for communities and governments. Factors considered to drive national research excellence are world class infrastructure, a highly skilled research workforce and critical mass in areas of research engagement. Crucial is stable, reliable funding over the long term for a high performing national research sector.

\section{Conclusion}

Despite encouraging gains since the 1960s, Indigenous people continue to be underrepresented in Australia's higher education sector. While Indigenous PhD commencement and enrolment rates are trending upward, it is starting from such a low base that, at current rates of increase, the numbers of Aboriginal and Torres Strait Islanders needed to reach critical mass are many generations away. Increasing the completion rate of Indigenous research post-graduate students will, as is the case for all postgraduates, require adequate time and training to develop and master key research skills.

Despite this requirement, the sector-wide commitment to, and program implementation of, support for Indigenous researchers tend to be ad hoc, often short term, with success and innovation not specifically rewarded. The Review of Higher Education Access and Outcomes for Aboriginal and Torres Strait Islander Peoples $(2012,110)$ in 2012 found that Indigenous research capacity building was almost non-existent. The only exceptions were the University of Melbourne and QUT, who offered capacity building programs. NIRAKN is building the research capacity of early to mid-career researchers and postgraduate students, but grant funding is only until 2017.

Universities advise the government that they are contributing to the national research effort through producing knowledge and highly skilled graduate students. This contribution needs to extend to producing highly skilled and knowledgeable Indigenous graduates, which requires Indigenous research and research capacity building to be included as part of a university's research training program.

Indigenous researchers are acutely aware that in every socio-economic indicator our people are not thriving, nor living as well as other Australians. Indigenous researchers want to take responsibility for Indigenous research, but, to realise the long-term potential of Indigenous research, requires the effort of both universities and the government. Universities can work with the Indigenous higher education sector to develop a practical approach to assess the quality and impact of Indigenous research to enable enriching the national research effort.

The current approach to Indigenous research and research capacity building by most universities comprises the potential impact that our research effort can make to improve the living conditions of Indigenous people. It is incumbent upon universities to develop an Indigenous research strategy that includes a funding model for long-term sustainability and productivity. To achieve this aim, Indigenous research and research capacity building needs to be identified as a priority area for development and, as with mainstream research, training funds can be allocated from the university's research block funding 
grant. To this end, it is imperative that an Indigenous research strategy includes support and expansion of an Indigenous research workforce. The ARC and the NHMRC have recognised the need for financial investment and have committed to capacity building with the Indigenous Discovery scheme and the NHMRC Road Map (2002) to improve Indigenous health, but this is not enough. University investment in stable and properly funded Indigenous research and research capacity building is critical to achieving Indigenous research success and our success becomes part of a university's success.

\section{References}

Behrendt, Larissa, Steven Larkin, Robert Griew and Patricia Kelly. 2012. Review of higher education access and outcomes for Aboriginal and Torres Strait Islander people: Final report. Canberra: Department of Industry, Innovation, Science, Research and Tertiary Education.

Department of Education and Department of Industry. 2014. Boosting the commercial returns from research. Canberra.

McGagh, John, Helene Marsh, Mark Western, Peter Thomas, Andrew Hastings, Milla Mihailova, Matt Wenham. 2016. Review of Australia's Research Training System. Canberra: Australian Council of Learned Academies.

The Aboriginal and Torres Strait Islander Research Agenda Working Group of the NHMRC. 2002. The NHMRC Road Map: A Strategic Framework for Improving Aboriginal and Torres Strait Islander Health Through Research. Canberra.

Universities Australia. 2015. Universities Australia Submission to the Senate Committee Inquiry into the Higher Education and Research Reform Bill 2014. Canberra.

Universities Australia. 2017. Universities Australia Indigenous Strategy 2017-2020.

Canberra. 